\title{
How To Get Mechanistic Information from Partial Pressure- Dependent Current-Voltage Measurements of Oxygen Exchange on Mixed Conducting Electrodes
}

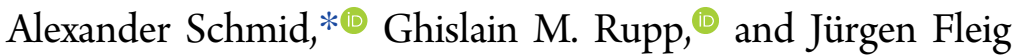 \\ Institute of Chemical Technologies and Analytics, Technische Universität Wien, Getreidemarkt 9, Vienna 1060, Austria
}

Supporting Information

\begin{abstract}
The oxygen incorporation and evolution reaction on mixed conducting electrodes of solid oxide fuel or electrolysis cells involves gas molecules as well as ionic and electronic point defects in the electrode. The defect concentrations depend on the gas phase and can be modified by the overpotential. These interrelationships make a mechanistic analysis of partial pressure-dependent current-voltage experiments challenging. In this contribution it is described how to

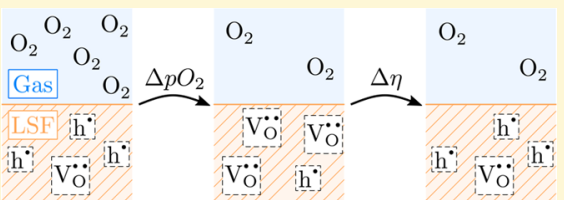
exploit this complex situation to unravel the kinetic roles of surface adsorbates and electrode point defects. Essential is a counterbalancing of oxygen partial pressure and $\mathrm{dc}$ electrode polarization such that the point defect concentrations in the electrode remain constant despite varying the oxygen partial pressure. It is exemplarily shown for $\mathrm{La}_{0.6} \mathrm{Sr}_{0.4} \mathrm{FeO}_{3-\delta}$ (LSF) thin film electrodes on yttria-stabilized zirconia how mechanistically relevant reaction orders can be obtained from current-voltage curves, measured in a three-electrode setup. This analysis strongly suggests electron holes as the limiting defect species for the oxygen evolution on LSF and reveals the dependence of the oxygen incorporation rate on the oxygen vacancy concentration. A virtual independence of the reaction rate from the oxygen partial pressure was empirically found for moderate oxygen pressures. This effect, however, arises from a counterbalancing of defect and adsorbate concentration changes.
\end{abstract}

\section{INTRODUCTION}

In the search for high-performance electrode materials in solid oxide fuel cells (SOFCs) and solid oxide electrolysis cells (SOECs), perovskite-type oxides are among the most promising candidates, ${ }^{1-10}$ and many different compositions, for example, $(\mathrm{La}, \mathrm{Sr}) \mathrm{MnO}_{3-\delta}(\mathrm{LSM}),{ }^{1-14}(\mathrm{La}, \mathrm{Sr})(\mathrm{Co}, \mathrm{Fe}) \mathrm{O}_{3-\delta}$ (LSCF), ${ }^{15-39}$ and $(\mathrm{Ba}, \mathrm{Sr})(\mathrm{Co}, \mathrm{Fe}) \mathrm{O}_{3-\delta}(\mathrm{BSCF}),{ }^{40-45}$ are being studied. The key property for the electrochemical performance of SOFC cathodes or SOEC anodes is the kinetics of the oxygen exchange reaction at the electrode surface. Understanding the factors that limit the oxygen reduction or evolution is therefore essential for improvement of the SOFC/SOEC electrode performance and the development of new electrode materials. Studying reaction rates of oxygen exchange and their dependence on the atmospheric oxygen pressure and electrode polarization can give valuable insights into the fundamental processes and the key parameters governing this reaction and thus help in determining the ratelimiting reaction step. ${ }^{46-52}$ Thus far, experimental evidence was found that oxygen vacancies can play an important role in the rate-limiting step of the oxygen reduction. ${ }^{53}$ For example, from investigations of $\mathrm{Ba}_{x} \mathrm{Sr}_{1-x} \mathrm{Co}_{y} \mathrm{Fe}_{1-y} \mathrm{O}_{3-\delta}$ it was concluded that the oxygen vacancy concentration and mobility are rate limiting for the oxygen reduction. ${ }^{54}$ Also, DFT calculations for $\mathrm{La}_{x} \mathrm{Sr}_{1-x} \mathrm{MnO}_{3-\delta}$ suggest oxygen vacancy mobility and concentration as limiting factors. ${ }^{14}$

Frequently, experimental studies aiming at mechanistic information are performed on thin film electrodes, as those strongly reduce limiting effects of gas or solid-state diffusion and can be manufactured in a well-defined geometry. Variation of oxygen partial pressure is then often employed in combination with impedance spectroscopy or conductivity relaxation measurements. ${ }^{13,34,39,54,55}$ There are also several studies discussing the effects of electrode polarization on the impedance. $^{12,19,20}$ Studies of the dc current voltage characteristics, however, are rather scarce on thin mixed ionic electronic conducting (MIEC) thin films, since determination of the true electrode overpotential (voltage loss at the working electrode) is often difficult in solid-state ionics. ${ }^{31,56,57}$ Two experimental approaches exist: Manufacturing sufficiently small working electrodes (microelectrodes) in order to ensure that the polarization resistance of the counter electrode is much smaller than that of the working electrode and can therefore be neglected. ${ }^{17,25,45}$ However, in previous experiments we found that the resistance of $\mathrm{La}_{0.6} \mathrm{Sr}_{0.4} \mathrm{FeO}_{3-\delta}$ (LSF) thin films can irreversibly increase by a factor of $10-100$ during the photolithographic microstructuring step. Alternatively, a reference electrode might be employed in a three-electrode setup, but in such three-electrode experiments much care is required to avoid measurement artifacts. ${ }^{58-63}$

In principle, studies varying the oxygen partial pressure as well as the electrode overpotential are highly attractive when aiming at mechanistic conclusions, e.g., at the rate-limiting step or the involved ionic and electronic defects, see sketch in Figure 1 (top). However, it is essential for data analysis and interpretation that both measurement parameters influence

Received: February 8, 2018

Revised: June 4, 2018

Published: June 4, 2018 


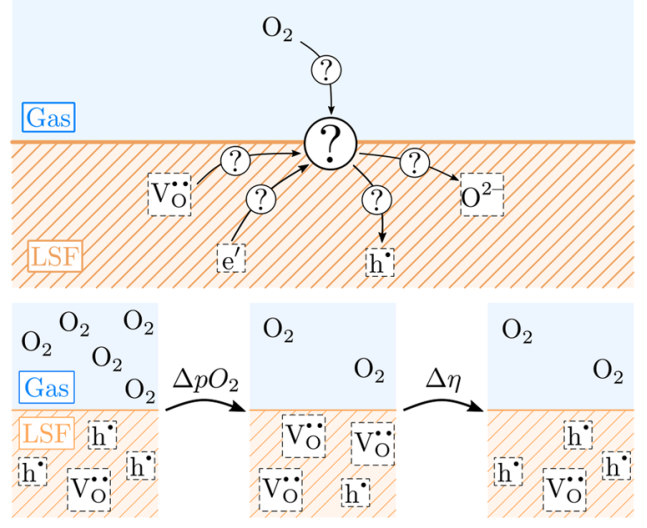

Figure 1. (Top) Sketch of the oxygen reduction reaction on LSF. Gasphase oxygen $\left(\mathrm{O}_{2}\right)$ forms oxide ions $\left(\mathrm{O}^{2-}\right)$ by filling oxygen vacancies $\left(\mathrm{V}_{\mathrm{O}}^{\bullet}\right)$. Whether electrons are supplied from the valence band (thus forming electron holes $\left(\mathrm{h}^{\bullet}\right)$ ) or the conduction band (defect electrons $\left.\left(\mathrm{e}^{\prime}\right)\right)$ is not known. (Bottom) Changing the oxygen partial pressure $p_{\mathrm{O}_{2}}$ modifies the defect concentrations in the electrode. By counterbalancing these $p_{\mathrm{O}_{2}}$-induced changes with a different overpotential $\eta$, the oxygen partial pressure can be varied while keeping defect concentrations constant.

the reaction rates in multiple ways. First, the oxygen partial pressure affects the adsorbate species and, via the oxygen chemical potential in the electrode, the defect concentrations. Second, the electrode polarization does not simply translate to an electrostatic driving force at the decisive interface, as in the Butler-Volmer model of aqueous electrochemistry, but instead acts primarily upon the oxygen chemical potential in the electrode and thus on the defect concentrations. ${ }^{23,49,64,65}$ Furthermore, oxygen partial pressure as well as overpotential may also affect the surface potential step. Hence, both experimentally accessible measurement parameters modify the reaction rates in multiple ways, and this convolution of several effects complicates the interpretation of oxygen partial pressuredependent current voltage curves. This is also discussed by Chueh et al., who approached the problem by simulating the reaction rates for different reaction mechanisms and comparing the partial derivatives with respect to oxygen partial pressure and overpotential. ${ }^{48}$

In this work, we introduce a simple but broadly applicable approach for analyzing and interpreting partial pressuredependent current voltage data of the oxygen exchange reaction on a mixed conducting thin film electrode. The analysis is based on the rate equation model suggested in ref 65 . By properly combining overpotential and oxygen partial pressure changes, reaction rates can be studied for fixed defect chemistry in the electrode, despite varying oxygen partial pressure, see Figure 1 (bottom). This procedure gives access to the true reaction orders of the oxygen release and incorporation reactions with respect to the relevant adsorbate species (determined by the gas phase) and the defect species in the solid phase. The novel approach is exemplified for LSF thin film electrodes on an yttria-stabilized zirconia electrolyte and reveals important mechanistic information on the decisive defect species for oxygen evolution and oxygen incorporation.

\section{EXPERIMENTAL SECTION}

Double-side-polished yttria-stabilized zirconia (100) single crystals (Crystec) $\left(5 \times 5 \times 1 \mathrm{~mm}^{3}\right)$ were used as electrolyte substrates. A reference electrode was produced by brushing a LSF/Pt-paste mixture into a notch around the circumference of the substrate and sintering in air for $2 \mathrm{~h}$ at $850{ }^{\circ} \mathrm{C}$. Platinum current collector grids of $30 / 5 \mu \mathrm{m}$ mesh/strip width and $100 \mathrm{~nm}$ thickness were prepared on both sides of the substrates by lift-off lithography and magnetron sputter deposition (BAL-TEC MED 020) to ensure complete and homogeneous electrode polarization. Dense $\mathrm{La}_{0.6} \mathrm{Sr}_{0.4} \mathrm{FeO}_{3-\delta}$ (LSF) thin film working electrodes were fabricated by pulsed laser deposition (PLD) on top of these current collectors. A cross-section scanning electron microscope (SEM) image of such an LSF film is shown in the Supporting Information (Figure S2). The PLD target was made from LSF powder (Sigma-Aldrich) by cold isostatic pressing $(150 \mathrm{MPa})$ and sintering in air $\left(12 \mathrm{~h}, 1200{ }^{\circ} \mathrm{C}\right)$. Ablation was done at $600^{\circ} \mathrm{C}$ substrate temperature and 0.04 mbar oxygen (Alphagaz, 99.995\%) using a $\mathrm{KrF}$ excimer laser (Complex Pro 201F, $248 \mathrm{~nm}$ ) with laser pulses of 400 $\mathrm{mJ}$ at $5 \mathrm{~Hz}$. The target to substrate distance was $6 \mathrm{~cm}$. Porous $\mathrm{La}_{0.6} \mathrm{Sr}_{0.4} \mathrm{CoO}_{3-\delta}$ (LSC) counter electrodes were made by PLD (400 $\mathrm{mJ}, 5 \mathrm{~Hz}, 6 \mathrm{~cm})$ at $450{ }^{\circ} \mathrm{C}$ and 0.4 mbar oxygen. A sketch of the resulting three-electrode samples is shown in the Supporting Information (Figure S1).

Working and counter electrodes were contacted by clamping the sample between two platinum sheets; the reference electrode was contacted with platinum thread around the sample circumference. Direct current measurements were performed at $600{ }^{\circ} \mathrm{C}$ in different oxygen/nitrogen mixtures (from $2.5 \times 10^{-4}$ to 1 bar oxygen) using a Novocontrol PotGal electrochemical test station and a Novocontrol Alpha frequency analyzer in potentiostat mode. At each oxygen partial pressure, one cathodic bias sweep (from 0 to -600 to $0 \mathrm{mV}$ ) followed by one anodic bias sweep (from 0 to 600 to $0 \mathrm{mV}$ ) was performed in steps of $50 \mathrm{mV}$. Additionally, impedance spectra were measured in all $\mathrm{O}_{2} / \mathrm{N}_{2}$ mixtures (from $10^{6}$ to $10^{-1} \mathrm{~Hz}, 10 \mathrm{mV}$ rms without de voltage). The total measurement time was about $30 \mathrm{~min}$ per atmosphere. Within these short time spans degradation of the LSF surface resistance was very small, in accordance with the almost identical currents found for the two branches of a bias sweep.

\section{RESULTS}

First, impedance spectra without dc voltage were measured at oxygen partial pressures between $2.5 \times 10^{-4}$ bar and 1 bar oxygen. The spectra show one dominant low-frequency semicircle feature and parts of an additional arc in the highfrequency domain. These impedance spectra were fitted to an equivalent circuit consisting of a parallel R-CPE element in series with a resistance $R_{\text {Offset }}$. The constant phase element (CPE) was used to model an imperfect capacitor. ${ }^{66}$ The measured spectra and the corresponding fit results are shown in the Supporting Information (Table S1 and Figure S3). Earlier studies revealed that the main arc of such spectra reflects the oxygen exchange resistance at the electrode surface and that the across plane oxygen transport resistance in these or similar mixed conducting thin film electrodes is negligible. ${ }^{18,20,25,45}$ Moreover, the electrode area above the Pt current collector grid was shown to be inactive for oxygen exchange. ${ }^{25}$ The values obtained for resistances and capacitances were thus normalized to the active area (approximately $73 \%$ of the total LSF area), yielding an oxygen exchange resistance of $13 \Omega \mathrm{cm}^{2}$ and a capacitance of $3.3 \mathrm{mF} \mathrm{cm}{ }^{-2}$ at $600{ }^{\circ} \mathrm{C}$ in 210 mbar oxygen. These values are comparable to data for oxygen surface exchange and chemical capacitance of similar LSF films reported in the literature. ${ }^{25}$ The resistive high-frequency offset, $R_{\text {Offset }}$ of $60-70 \Omega$ is attributed to the ionic resistance of the electrolyte and minor contributions from the wiring, i.e., the sum of all voltage losses not caused by the surface exchange reaction.

The resistance $R_{\text {Offset }}$ is used to calculate the electrode overpotential $\eta$ according to 


$$
\eta=U_{\mathrm{DC}}-I_{\mathrm{DC}} \cdot R_{\mathrm{Offset}}
$$

where $U_{\mathrm{DC}}$ is the measured voltage between the working and the reference electrode and $I_{\mathrm{DC}}$ is the measured current through the working and counter electrode. This overpotential acts as the driving force for the net oxygen incorporation or oxygen evolution at the LSF surface. After this first impedance characterization the partial pressure-dependent dc polarization sweeps were performed.

Figure 2 shows a $3 \mathrm{D}$ plot of the entire experimental data set, i.e., the measured net current density $j$ (normalized to the active

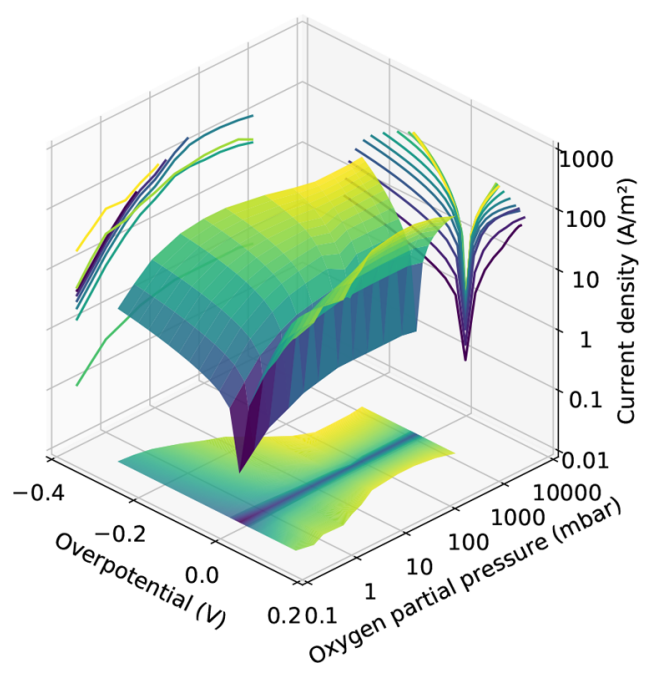

Figure 2. Measured net current density at $600{ }^{\circ} \mathrm{C}$ as a function of oxygen partial pressure and overpotential. Projections of this data set to the $j-p_{\mathrm{O}_{2}}$ plane (i.e., current vs oxygen partial pressure at fixed overpotentials) and the $j-\eta$ plane (i.e., current vs overpotential curves at fixed oxygen partial pressures) are indicated on the vertical sides of the figure. Bottom shows a projection of the data set to the $\eta-p_{\mathrm{O}_{2}}$ plane. electrode area, approximately $73 \%$ ) as a function of electrode overpotential and oxygen partial pressures from $0.25 \mathrm{mbar}$ to 1 bar $\mathrm{O}_{2}$ for an LSF thin film electrode at $600{ }^{\circ} \mathrm{C}$. Projections of this data set to the $j-\eta$ plane for selected oxygen partial pressures (i.e., current density vs overpotential curves) are displayed in Figure 3. The highest overpotential values could be experimentally achieved in the cathodic regime and at low oxygen partial pressure due to the high working electrode resistance and thus small relative electrolyte losses. At high oxygen partial pressure and in the anodic regime the working electrode resistance becomes low and thus the relative voltage drop in the electrolyte increases, leading to a smaller attainable overpotential range. A first obvious result is the absence of any strong $p_{\mathrm{O}_{2}}$ dependence of the $j-\eta$ curves for oxygen partial pressures above 25 mbar, see Figure 3, right.

From the measured current density vs overpotential and oxygen partial pressure data, projections to the $j-p_{\mathrm{O}_{2}}$ plane, i.e., current density vs oxygen partial pressure curves at constant overpotentials, are accessible. However, since during these experiments only the dc voltage between the working and the reference electrode $U_{\mathrm{DC}}$ is controlled, the specific electrode overpotentials $\eta$ differ for different oxygen partial pressures despite the same nominal dc voltage. Hence, these curves were obtained by linear interpolation of the current density vs overpotential curves between the two closest measured data points. This point by point interpolation was necessary since simple analytical functions such as exponentials cannot describe the experimental data sufficiently. The resulting plots are shown in Figure 4. Separating these data into high oxygen partial pressure (>10 mbar) and low oxygen partial pressure $(<10$ mbar) and into cathodic and anodic polarization yielded four different regimes.

Under anodic polarization and at high oxygen partial pressures, the oxygen evolution exhibits only little oxygen partial pressure dependence. For the highest oxygen partial pressures $(0.5-1 \mathrm{bar})$ the oxygen evolution rate shows even a slightly negative trend versus the oxygen partial pressure. At first glance, this part of the curve seems easy to understand,
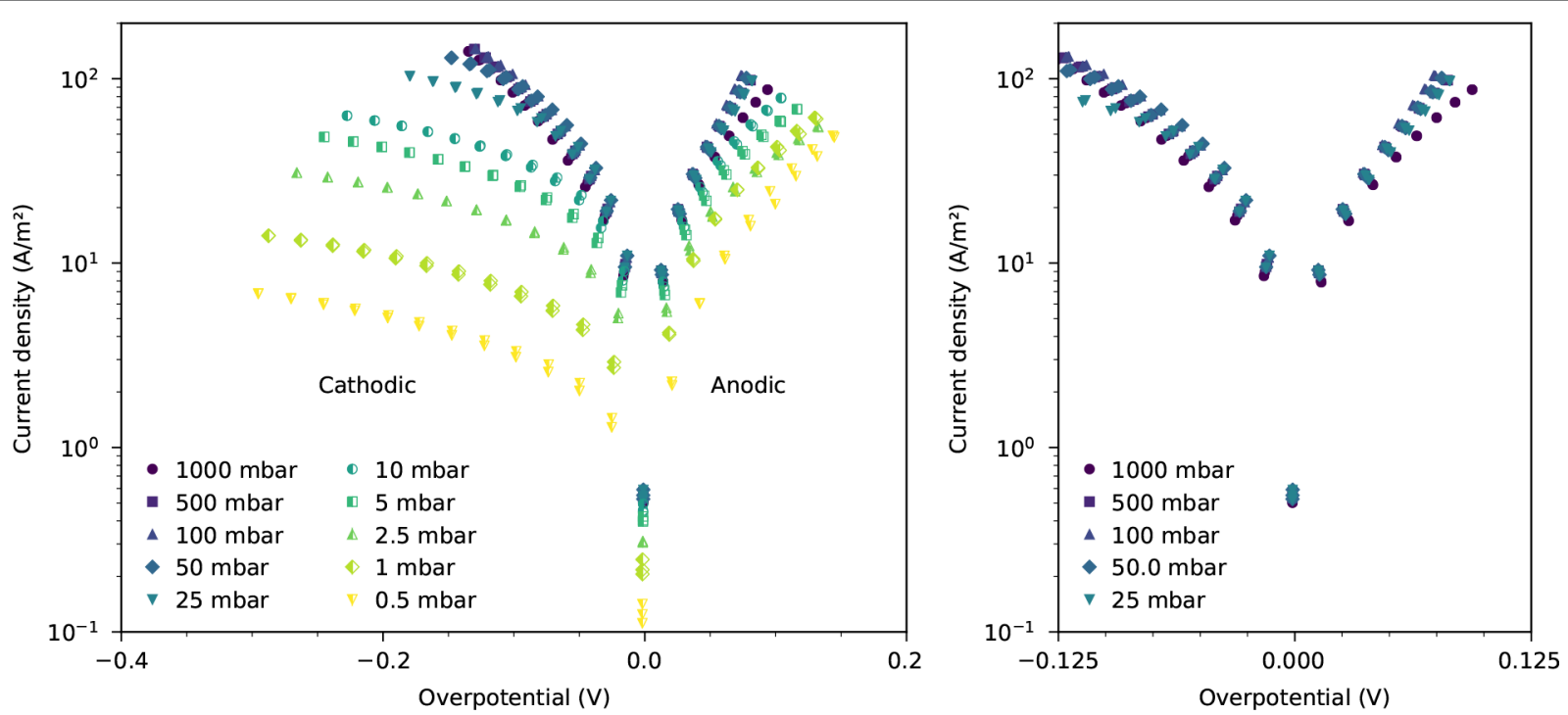

Figure 3. Current density versus overpotential curves of LSF thin film electrodes at $600{ }^{\circ} \mathrm{C}$ in various oxygen partial pressures. (Left) Whole data set; (right) selected high $p_{\mathrm{O}_{2}}$ curves $(25-1000 \mathrm{mbar}$ ). Each $\eta-j$ curve consists of one cathodic bias sweep (from 0 to -600 to $0 \mathrm{mV}$ set voltage) and one anodic bias sweep (from 0 to 600 to $0 \mathrm{mV}$ set voltage) measured consecutively. 

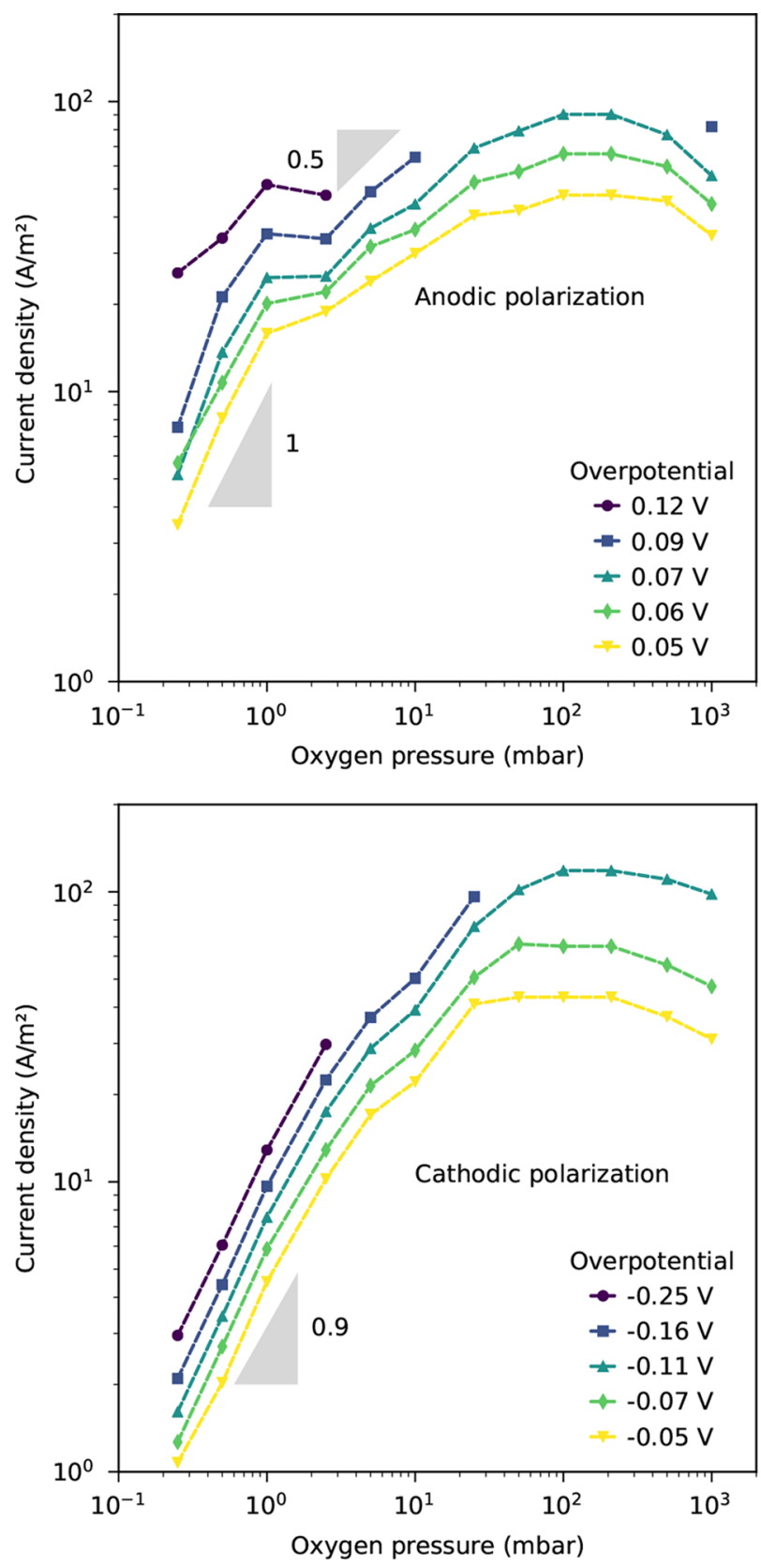

Figure 4. Current versus oxygen partial pressure for different anodic (top) and cathodic (bottom) overpotentials. Data were obtained from the measurement results shown in Figure 3 by linear interpolation between the two nearest data points.

assuming oxygen in the gas either being irrelevant for oxygen evolution or even hindering it. However, below 10 mbar oxygen the oxygen release rate quite surprisingly decreases with decreasing oxygen partial pressure. Here, the empirical reaction order with respect to $p_{\mathrm{O}_{2}}$ is in the range of $0.5-1$, see Figure 4 (top), meaning that a higher product concentration, $p_{\mathrm{O}_{2}}$, enhances the reaction rate of oxygen evolution.

Under cathodic polarization and at oxygen partial pressures below 10 mbar, the oxygen incorporation rates distinctly increase with increasing $p_{\mathrm{O}_{2}}$, see Figure 4 (bottom). This rateenhancing effect of oxygen seems intuitively understandable, and simple models of $p_{\mathrm{O}_{2}}$-dependent adsorbate concentrations suggest a slope of either 1 for molecular oxygen involved in the rate-limiting step or 0.5 for atomic oxygen. However, here the empirical reaction order is close to 0.9. Moreover, above 10 mbar the reaction order with respect to gaseous oxygen surprisingly decreases to almost zero and even gets slightly negative above 0.2 bar.

Altogether it is obvious that empirical $j-p_{\mathrm{O}_{2}}$ curves can be very nontrivial, and a straightforward interpretation is not possible. The same is true for the $j-\eta$ data in Figure 3, where a simple Tafel analysis (linear lines in the $\log (j)$ vs $\eta$ plots) fails for many curves. This is due to the nontrivial and largely nonelectrostatic effects of the overpotential as discussed in the following. ${ }^{49,65}$

\section{DATA ANALYSIS AND DISCUSSION}

Rate Equation and General Approach. In an empirical analysis of the $j-\eta$ and $j-p_{\mathrm{O}_{2}}$ curves in Figures 3 and 4 , one might assume that the anodic oxygen evolution current density $j_{\mathrm{a}}$ and the cathodic oxygen reduction current density $j_{\mathrm{c}}$ can be split into constant prefactors $j_{\mathrm{c}}^{0}, j_{\mathrm{a}}^{0}$ and voltage and partial pressure-dependent factors

$$
\begin{aligned}
& j_{\mathrm{c}}=-j_{\mathrm{c}}^{0} f_{\mathrm{c}}(\eta) p \mathrm{o}_{2}^{\nu_{\mathrm{c}, \text { emp }}} \\
& j_{\mathrm{a}}=+j_{\mathrm{a}}^{0} f_{\mathrm{a}}(\eta) p \mathrm{o}_{2}^{\nu_{\mathrm{a}, \mathrm{emp}}}
\end{aligned}
$$

The total current density is $j=j_{\mathrm{c}}+j_{\mathrm{a}} \cdot \nu_{\mathrm{a}, \mathrm{emp}}$ and $\nu_{\mathrm{c}, \mathrm{emp}}$ are the empirical reaction orders with respect to gaseous oxygen; $f_{\mathrm{a}}$ and $f_{\mathrm{c}}$ are functions of the overpotential $\eta$. For sufficiently anodic polarization, $j_{\mathrm{a}} \gg j_{\mathrm{c}}$ is valid, and the anodic reaction order $\nu_{\mathrm{a}, \mathrm{emp}}$ can be extracted from the anodic branch of the $j-p_{\mathrm{O}_{2}}$ plots in Figure 4 . In the same way, $\nu_{c, \text { emp }}$ can be extracted from the cathodic branch. However, as already discussed above, the gaseous oxygen affects both the adsorbate species and the defect concentrations in the electrode. Thus, there is no simple mechanistic meaning behind the empirical reaction orders.

In the following, a different approach is therefore introduced, which does not rely on the experimental parameters $p_{\mathrm{O}_{2}}$ and $\eta$ but instead considers the truly reacting local species (surface adsorbates and point defects in the solid electrode) and the local electrostatics at the decisive gas/solid interface (surface potential). A rate equation was suggested in ref 65 to deconvolute the effects of adsorbates and defects. An alternative approach was described by Chueh et al. and specified for different reaction mechanisms. ${ }^{48}$ In the Supplementary Information, a specific rate equation is deduced for an exemplary reaction mechanism of electrochemical oxygen surface exchange. When generalizing this deviation for other possible mechanisms we get

$$
j_{\mathrm{c}}=-j_{\mathrm{c}}^{0} c_{\mathrm{D}, \mathrm{c}}^{\nu_{\mathrm{D}, \mathrm{c}}} \mathrm{po}_{2}^{\nu_{\mathrm{p}, \mathrm{c}}} \exp \left(\frac{-\beta e \chi_{0}}{k T}\right) \exp \left(\frac{-\beta e \Delta \chi}{k T}\right)
$$

In eq $4 c_{D, c}$ is the relevant defect species concentration and $\nu_{\mathrm{D}, \mathrm{c}}$ is the respective reaction order. If more than one defect has to be considered this factor has to be replaced by a product such as $c_{\mathrm{D}_{1}}^{\nu_{\mathrm{D}_{1}}} c_{\mathrm{D}_{2}}^{\nu_{\mathrm{D}_{2}}} . \nu_{\mathrm{p}, \mathrm{c}}$ is the true reaction order with respect to the oxygen partial pressure, $p_{\mathrm{O}_{2}}$. In contrast to the empirical reaction order in eqs 2 and 3, this "true" oxygen reaction order only involves the effect of gas-phase oxygen via oxygen adsorbates but not effects via $p_{\mathrm{O}_{2}}$-dependent defect concentrations in the electrode. The symbols $\chi_{0}$ and $\Delta \chi$ represent the 
surface potential step in equilibrium and its change under current, respectively; $\Delta \chi$ might largely come from changes of charged adsorbates under current. ${ }^{49} \beta$ is a factor that depends on the reaction mechanism. The prefactor $j_{\mathrm{c}}^{0}$ may depend on the concentration of catalytically active sites, if those are not the defects already considered by $c_{\mathrm{D}}$. Symbols $k, T$, and $e$ denote Boltzmann constant, temperature, and elementary charge. In the same way, the oxygen evolution current density can be described by an equation however with usually different relevant defect species and reaction orders.

The experimental parameter $\eta$ acts on the defect concentrations $c_{\mathrm{D}}$ but may also affect the surface potential $\left(\chi_{0}, \Delta \chi\right){ }^{49,65}$ The experimentally given oxygen partial pressure affects the adsorbate concentration and the oxygen chemical potential in the solid phase and thus the defect concentrations. Furthermore, $p_{\mathrm{O}_{2}}$ may influence the surface potential via charged adsorbates. In the following, we simplify this very complex situation by assuming that, at least for low oxygen partial pressures, the surface potential step does not change much with voltage and $p_{\mathrm{O}_{2}}$. XPS studies on LSF support this assumption. $^{30}$ Thus, $p_{\mathrm{O}_{2}}$ mainly affects rates by adsorbate concentrations and the electrode defect chemistry, while the overpotential acts mainly by changing the defect concentrations. We thus get a simplified relation from eq 4, with prefactor $j^{\prime}{ }_{c}^{0}$ that includes the constant $\chi$ and $\Delta \chi$ terms

$$
j_{\mathrm{c}}=-j_{\mathrm{c}}^{0} c_{\mathrm{D}}^{\nu_{\mathrm{D}}} p_{\mathrm{O}_{2}}^{\nu_{\mathrm{p}}}
$$

Since the defect concentration depends on the oxygen chemical potential in the electrode $\mu_{\mathrm{O}}$ we may express $c_{\mathrm{D}}^{\nu_{\mathrm{D}}}$ by the relation ${f^{\prime}}^{\prime}\left(\mu_{\mathrm{O}}\right)$ and thus get

$$
j_{\mathrm{c}}=-j_{\mathrm{c}}^{\prime 0} f_{\mathrm{c}}^{\prime}\left(\mu_{\mathrm{O}}\right) p_{\mathrm{O}_{2}}^{v_{\mathrm{p}}}
$$

This equation explicitly expresses that the cathodic current density is determined by gas adsorbates (via $p_{\mathrm{O}_{2}}^{\nu_{\mathrm{p}}}$ ) and by the defect chemistry $\left(\right.$ via $\left.f^{\prime}{ }_{c}\left(\mu_{\mathrm{O}}\right)\right)$ in contrast to the mechanistically much less insightful eq 2 .

On the basis of this model we can now approach a mechanistic interpretation of our experimental data, i.e., the current density as a function of oxygen partial pressure and overpotential. The main advantage of this analysis relies on the fact that the defect concentrations can be tuned independently by either oxygen partial pressure or overpotential. More specifically, the defect concentrations are determined by the chemical potential of oxygen in the electrode $\mu_{\mathrm{O}}$, which depends on the experimental parameters $p_{\mathrm{O}_{2}}$ and $\eta$ according to $^{23,67}$

$$
\mu_{\mathrm{O}}=2 e \eta+\frac{k T}{2} \ln \left(\frac{p_{\mathrm{O}_{2}}}{1 \mathrm{bar}}\right)
$$

Here the oxygen chemical potential is referenced to 1 bar oxygen $\left(\mu_{\mathrm{O}}=0\right.$ for 1 bar and $\left.\eta=0 \mathrm{~V}\right)$. Hence, a certain defect chemical state can be established by different combinations of oxygen partial pressure and overpotential. By an appropriate choice of $\eta$ we can thus counterbalance any $p_{\mathrm{O}_{2}}$ change such that the oxygen chemical potential and thus the defect concentrations remain fixed.

In order to exploit the advantages of eq 6, we first have to transform our data set from $j\left(\eta, p_{\mathrm{O}_{2}}\right)$ to $j\left(\mu_{\mathrm{O}}, p_{\mathrm{O}_{2}}\right)$ by using the relation in eq 7 . Then a two-step analysis follows. First, we analyze the $j-p_{\mathrm{O}_{2}}$ dependency at fixed oxygen chemical potential and extract the true reaction order with respect to oxygen partial pressure. This true reaction order only involves the effect of adsorbed oxygen species and does not include any effect of defect concentrations. In terms of eqs 5 and 6 we fix $\mu_{\mathrm{O}}$, and thereby $c_{\mathrm{D}}$, and thus get $\nu_{\mathrm{p}}$. Second, from the $j-\mu_{\mathrm{O}}$ curves at fixed oxygen partial pressures we can extract the dependencies on the oxygen chemical potential (and thus on the defect chemistry) in the electrode, i.e., $f^{\prime}{ }_{c}\left(\mu_{\mathrm{O}}\right)$ in eq 6. By comparing these dependencies to the Brouwer diagram of the electrode material (defect concentrations vs oxygen chemical potential), we can get information on the relevant defect species. In the following, this approach is exemplified for the experimental LSF data shown above.

\section{ANALYSIS OF LSF CURRENT-VOLTAGE CURVES}

Recalculation of the Data Set. From the experiments, current density vs overpotential curves for different oxygen partial pressures were obtained. This $j\left(\eta, p_{\mathrm{O}_{2}}\right)$ data set was converted to current density vs oxygen chemical potential data, $j\left(\mu_{\mathrm{O}}, p_{\mathrm{O}_{2}}\right)$ by eq 7 . This is essentially a shift of the current density vs overpotential curves (Figure 3 ) by the Nernst voltage term in eq 7. Figure 5 displays selected current density vs oxygen chemical potential curves for the anodic and cathodic branch. The shape of these curves corresponds to the $f^{\prime}{ }_{c}\left(\mu_{\mathrm{O}}\right)$ term in eq 6 and its anodic counterpart $f^{\prime}{ }_{\mathrm{a}}\left(\mu_{\mathrm{O}}\right)$.

From this recalculated data set, the current density vs oxygen partial pressure characteristics at constant oxygen chemical potentials were extracted in the same manner as described above for the $j-\eta$ curves, i.e., by linear interpolation between the two closest data points. From the resulting plots we can get the partial pressure dependency, i.e., the $p_{\mathrm{O}_{2}}{ }^{{ }^{\mathrm{p}}}$ factor in eq 6 . Several current density vs $p_{\mathrm{O}_{2}}$ curves are shown in Figure 6 . The number of data points on these curves strongly differs for different oxygen chemical potentials. This is simply due to the fact that some oxygen chemical potentials were only accessible in a limited $p_{\mathrm{O}_{2}}$ range in the experiment. For example, in the anodic regime high oxygen chemical potentials were only reached at high $p_{\mathrm{O}_{2}}$. For low oxygen partial pressures, the overpotentials in the experiment were not sufficiently high to induce large shifts toward a high oxygen chemical potential. In the cathodic regime, on the other hand, the slightly negative oxygen chemical potential range with respect to the reference state at 1 bar was only accessible for high oxygen partial pressures. The resulting data set can again be divided into a high $p_{\mathrm{O}_{2}}$ regime and a low $p_{\mathrm{O}_{2}}$ regime for both anodic and cathodic branches. These are discussed below, based on the following defect chemical model for bulk LSF.

Defect Model of Bulk LSF. A quantitative bulk defect model of LSF is described in refs 68 and 69. The main defect species in this model are oxygen vacancies $\mathrm{V}_{\mathrm{O}}^{\bullet \bullet}$, electrons $\mathrm{Fe}_{\mathrm{Fe}}^{\prime}$, and electron holes $\mathrm{Fe}_{\mathrm{Fe}}^{\bullet}$. The reaction enthalpies and entropies for electron/hole pair formation $\left(2 \mathrm{Fe}_{\mathrm{Fe}}^{\mathrm{x}} \rightleftharpoons \mathrm{Fe}_{\mathrm{Fe}}^{\bullet}+\mathrm{Fe}_{\mathrm{Fe}}^{\prime}\right)$ and oxygen incorporation reaction $\left(\mathrm{V}_{\mathrm{O}}^{\bullet \bullet}+1 / 2 \mathrm{O}_{2}+2 \mathrm{Fe}_{\mathrm{Fe}}^{\mathrm{x}} \rightleftharpoons\right.$ $\left.\mathrm{O}_{\mathrm{O}}^{\mathrm{x}}+2 \mathrm{Fe}_{\mathrm{Fe}}^{\bullet}\right)$ were determined via thermogravimetry and coulometric titration, see Table $1 .^{28}$ From these data, the defect concentrations can be calculated, and Figure 7 shows the corresponding Brouwer diagram for LSF at $600{ }^{\circ} \mathrm{C}$.

Mechanistic Analysis of Anodic Oxygen Evolution. For low oxygen partial pressures and anodic polarization, the 

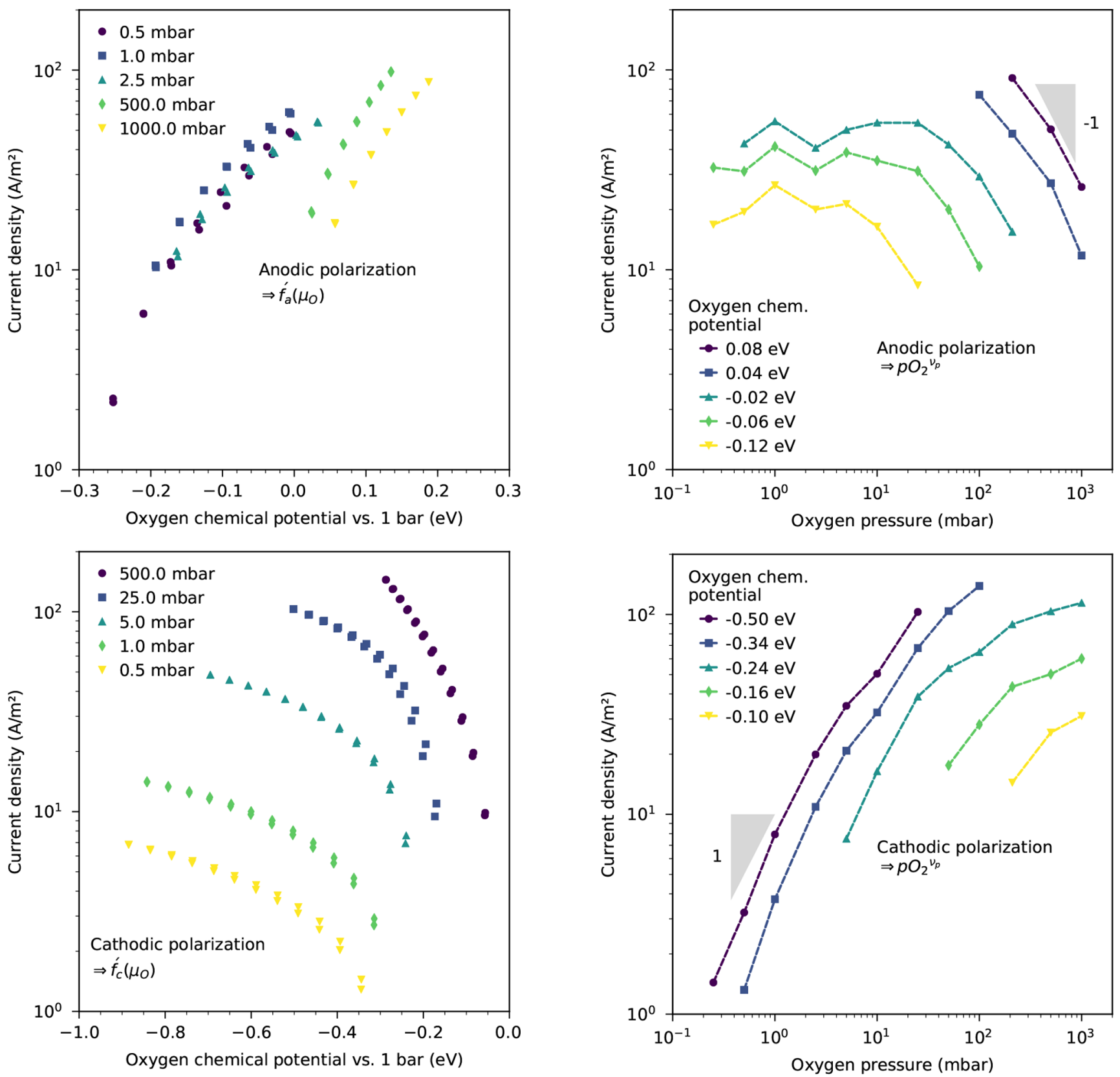

Figure 5. Current density vs oxygen chemical potential (vs 1 bar $\mathrm{O}_{2}$ ) for anodic (top) and cathodic (bottom) polarization at $600{ }^{\circ} \mathrm{C}$. Each curve consists of data from one bias sweep (from 0 to \pm 600 to $0 \mathrm{mV}$ set voltage) for different oxygen partial pressures in the gas.

current density vs oxygen chemical potential curves approximately coincide, see Figure 5 (top), i.e., the true reaction order with respect to gaseous oxygen $\nu^{\mathrm{p}}$ is almost zero, see Figure 6 (top). Thus, the surprisingly positive empirical reaction order mentioned above, see Figures 3 and 4, suggesting an acceleration of the oxygen evolution reaction by gas molecules, is only an indirect effect due to the dependence of defect concentrations on $p_{\mathrm{O}_{2}}$. Therefore, this phenomenon vanishes when keeping the defect chemistry $\left(\mu_{\mathrm{O}}\right)$ constant. As a first result of our analysis we can thus conclude that for low oxygen partial pressures the true reaction order of gas molecules is close to zero.

The dependency of the current density on the oxygen chemical potential at fixed $p_{\mathrm{O}_{2}}$ (Figure 5), on the other hand,

Figure 6. Current density vs oxygen partial pressure curves for several oxygen chemical potentials under anodic (top) and cathodic (bottom) polarization, extracted from the data in Figure 5 by linear interpolation. Oxygen chemical potential, and thus the defect chemical state in the electrode, is constant along each curve. Thus, only the adsorbate concentrations change with oxygen partial pressure.

Table 1. Thermodynamic Defect Data of $\mathrm{LSF}^{28}$

\begin{tabular}{lcc} 
& $\Delta H\left(\mathrm{~kJ} \mathrm{~mol}^{-1}\right)$ & $\Delta S(\mathrm{~J} \mathrm{~mol}$ \\
& -95.62 & $\mathrm{~K})$ \\
oxygen incorporation & 95.75 & -54.27 \\
electron/hole formation & -21.63 \\
\hline
\end{tabular}

reflects $f^{\prime}{ }_{\mathrm{a}}\left(\mu_{\mathrm{O}}\right)$ and thus the dependency on the defect concentrations, i.e., $c_{\mathrm{D}}^{\nu_{\mathrm{D}}}$ in eq 5 . These curves can be compared with the known relation between bulk defect concentrations and the oxygen chemical potential calculated from bulk data, ${ }^{28}$ see the Brouwer diagram in Figure 7. Only electron holes exhibit a similar shape as the current density vs oxygen chemical 


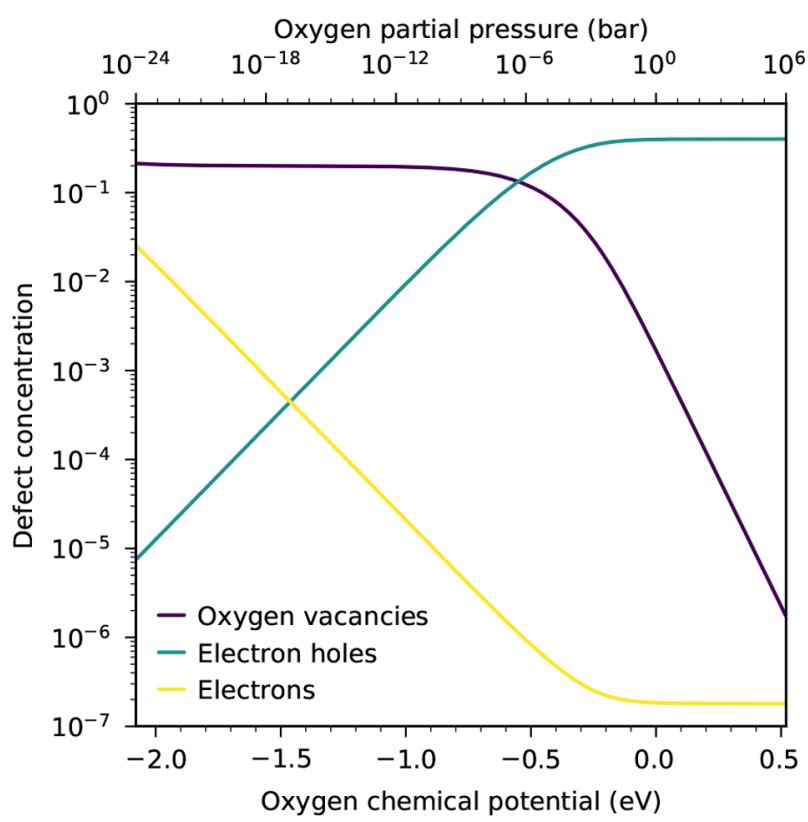

Figure 7. Brouwer diagram of LSF at $600{ }^{\circ} \mathrm{C}$, calculated from literature data on bulk LSF. ${ }^{28}$

potential curves, suggesting that electron holes are the defect species determining the oxygen evolution rate.

For a more detailed analysis, we may use the current density at a given oxygen chemical potential and plot it versus the electron hole concentration calculated from the defect model for this oxygen chemical potential. The resulting doublelogarithmic plot shows a clear correlation between electron holes and the oxygen evolution current density, see Figure 8 (top). The relation does not follow a simple power law and additionally shows an extremely high slope (roughly 20 on average), i.e., a very strong dependency of the oxygen evolution current density on the hole concentration. However, we have to keep in mind that the calculated bulk defect concentrations can severely differ from the local defect concentration at the surface. Simulations of the related perovskite material $\mathrm{LaCoO}_{3}$ revealed a lower formation energy of oxygen vacancies at the surface, resulting in a more reduced state of the surface and thus less electron holes compared with the bulk. ${ }^{70}$

Owing to the lack of experimental data on the exact defect chemical state of our LSF surfaces, we tried to consider the effect of such a reduced surface by simply shifting the bulk Brouwer diagram toward higher oxygen chemical potentials. We then used the shifted Brouwer diagrams to calculate the defect concentrations for the respective oxygen chemical potentials. For a $\mu_{\mathrm{O}}$ shift of $160 \mathrm{meV}$, i.e., a shift on the oxygen partial pressure axis by a factor of 70 , the resulting oxygen evolution current density versus electron hole concentration plot (Figure 8, bottom) shows a linear correlation between the electron hole concentration and the oxygen evolution rate in the double-logarithmic plot. Thus, a simple power law relation exists, and a fit revealed an exponent of 6.7. Owing to the given assumptions and uncertainties, we do not dare to interpret the exact value of 6.7 mechanistically, but such a high value strongly suggests involvement of multiple electron holes in the mechanism of oxygen evolution. However, these electron holes do not necessarily enter the ratedetermining step as reacting species but may also be included in preceding equilibrium steps.
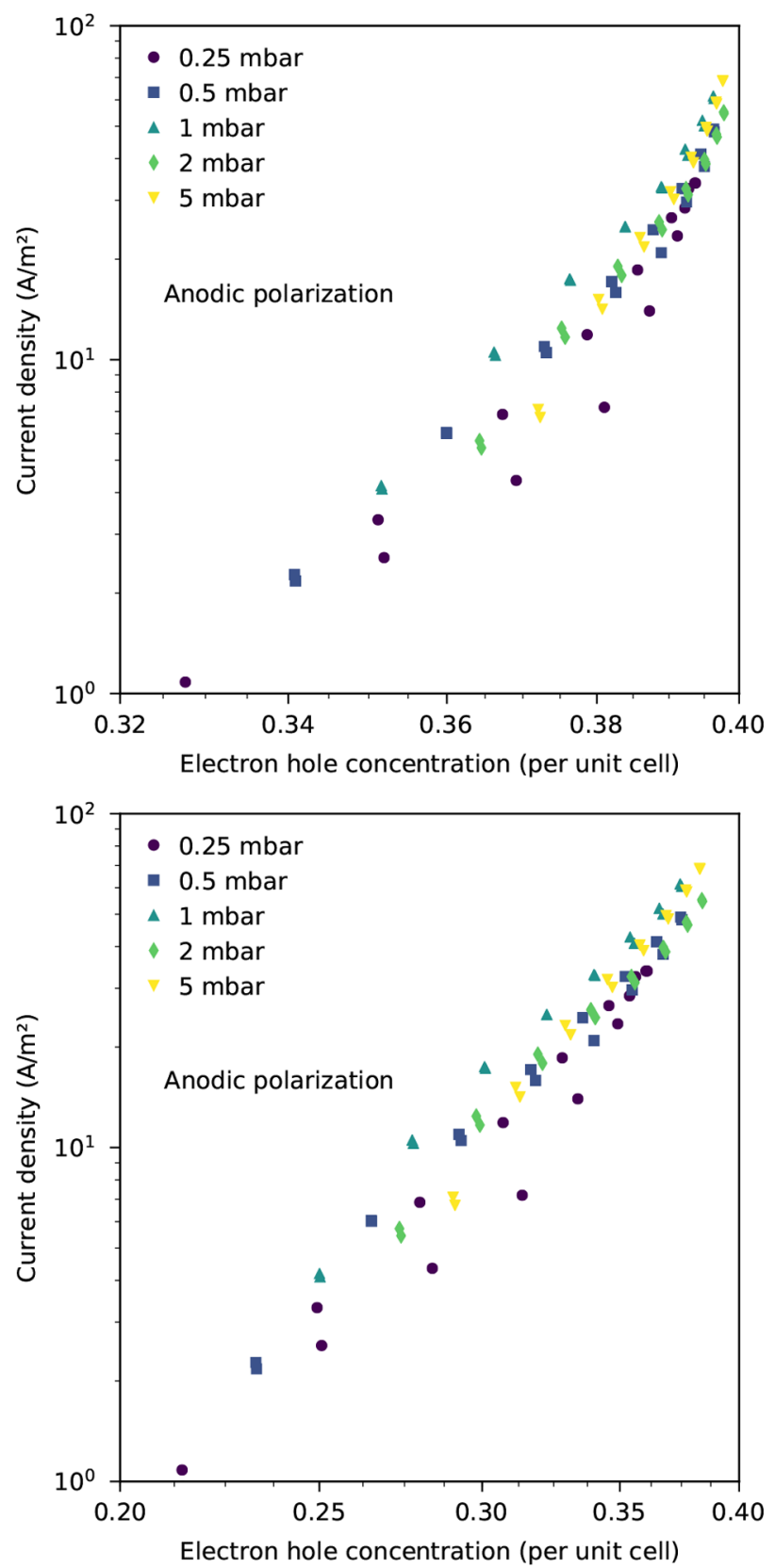

Figure 8. Oxygen evolution current density vs electron hole concentration. (Top) Hole concentrations were calculated based on the bulk defect model for LSF. ${ }^{28}$ (Bottom) Hole concentrations were calculated from a Brouwer diagram shifted to higher oxygen chemical potential by $160 \mathrm{meV}$.

In the anodic regime above $10 \mathrm{mbar} p_{\mathrm{O}_{2}}$ (Figure 6, top), the current density decreases with higher oxygen partial pressure, i.e., the true reaction order becomes negative. Since the defect chemistry is fixed, this effect has to be caused by gas adsorbate species. Hence, the only weak empirical dependence of the oxygen evolution rate on oxygen partial pressure (see Figure 4, top) turns out to be just an incidental counterbalancing between the true, negative reaction order of $p_{\mathrm{O}_{2}}$, and an accelerating effect due to the oxygen partial pressure-dependent defect concentrations. Possible explanations for this negative true reaction order are a blockage of catalytically active sites for oxygen evolution on the surface by gas adsorbates or a change in the surface potential step due to higher adsorbate coverages 
(only considered in eq 4). A gas diffusion limitation would still be reflected by an increase of the current with increasing $p_{\mathrm{O}_{2}}$. The defect chemical dependence of the current density, given by ${f^{\prime}}_{\mathrm{a}}\left(\mu_{\mathrm{O}}\right)$, again suggests an important role of electron holes, but a more quantitative analysis as for low $p_{\mathrm{O}_{2}}$ is beyond the scope of our study.

Mechanistic Analysis of Cathodic Oxygen Reduction. Under cathodic polarization and low $p_{\mathrm{O}_{2}}$, the current vs oxygen partial pressure plots at constant $\mu_{\mathrm{O}}$ (see Figure 6, bottom) reveal a clear dependence of the oxygen reduction current on the oxygen partial pressure, with a true reaction order close to 1. This true reaction order again reflects the pure effects of gas phase and adsorbate species and does not include any influence of defect chemistry. A true reaction order of 1 with respect to molecular oxygen suggests either molecular oxygen adsorbates of unknown charge being involved in the rate-determining step or gas diffusion/adsorption as rate-limiting step. The empirical reaction order of 0.9 found in our first analysis, see Figure 4, is thus a convolution of the true reaction order of 1 and a slightly negative indirect effect of $p_{\mathrm{O}_{2}}$ via an impact of $p_{\mathrm{O}_{2}}$ on defect concentrations. This negative impact of the oxygen partial pressure on the defect chemistry already hints at oxygen vacancies as the relevant defects, since their concentration decreases with increasing $p_{\mathrm{O}_{2}}$.

At high oxygen partial pressure and cathodic polarization (Figure 6, bottom), the true reaction order with respect to oxygen gas continually decreases and reaches almost zero. This is again a true gas species/adsorbate effect and not a result of changes in defect concentrations. It means that more gas species no longer accelerate the reduction rate via more adsorbates. The onset of this decrease in reaction order is at around 10-20 mbar oxygen partial pressure. Interestingly, this is exactly the pressure range where the oxygen partial pressure begins to have a negative effect on the anodic reaction rate, see Figure 6 (top). Moreover, in the same oxygen partial pressure range the $p_{\mathrm{O}_{2}}$ dependence of the polarization resistance from impedance spectroscopy changes its sign, see Figures S3 and S4 in the Supporting Information. A common mechanism behind these three observations is likely. As already mentioned above, the saturation of catalytically active sites with oxygen adsorbate species may be responsible. Another possible reason for the onset of deviations is a change in the surface potential, due to higher surface coverage of charged adsorbates for higher oxygen partial pressure.

The current density vs oxygen chemical potential curves at constant $p_{\mathrm{O}_{2}}$ reflect the influence of the defect chemistry on oxygen reduction, see Figure 5 (bottom). When comparing the shapes of the current density vs oxygen chemical potential curves and the defect concentrations in the Brouwer diagram (see Figure 7), we find a good agreement for oxygen vacancies. Therefore, we assume that oxygen vacancies are the limiting defect species for oxygen incorporation. Oxygen vacancies are also suggested in the literature as the rate-limiting defect species for oxygen incorporation on related perovskites of the $(\mathrm{La}, \mathrm{Sr}) \mathrm{MnO}_{3},(\mathrm{La}, \mathrm{Sr})(\mathrm{Co}, \mathrm{Fe}) \mathrm{O}_{3}$, and $(\mathrm{Ba}, \mathrm{Sr})(\mathrm{Co}, \mathrm{Fe}) \mathrm{O}_{3}$ families. $^{14,54,71}$

The current density as a function of calculated bulk oxygen vacancy concentration is shown in Figure 9 (top) for oxygen partial pressures of the entire investigated pressure range. To a first approximation, these curves exhibit close to linear relations between oxygen vacancy concentration and oxygen reduction
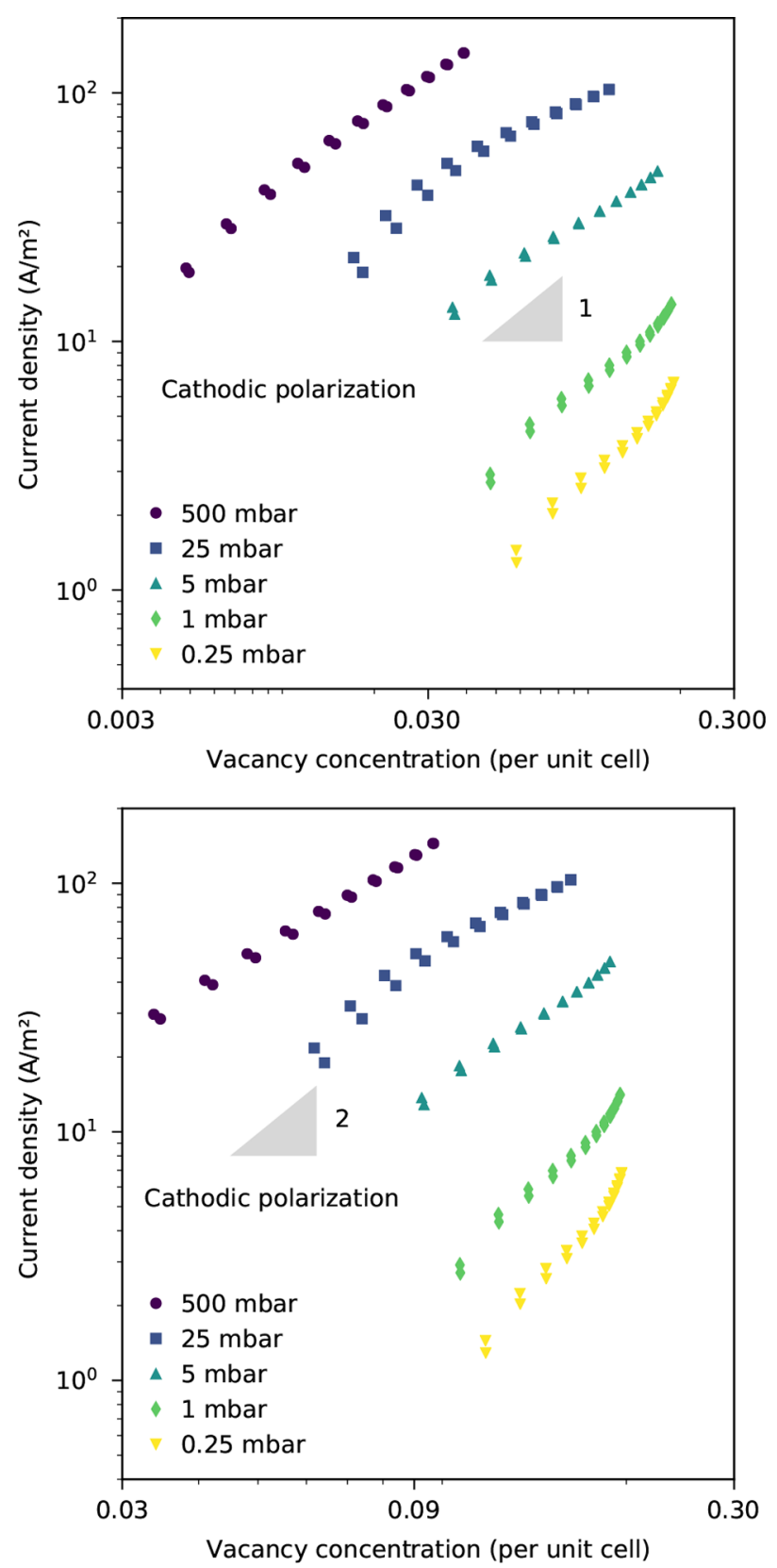

Figure 9. Oxygen incorporation current density vs oxygen vacancy concentration. (Top) Vacancy concentrations were calculated based on the bulk defect model for LSF. ${ }^{28}$ (Bottom) Vacancy concentrations were calculated from a Brouwer diagram shifted to higher oxygen chemical potential by $160 \mathrm{meV}$.

current density, indicating a reaction order close to one with respect to oxygen vacancies. For high concentrations of oxygen vacancies, however, the current densities deviate from the linear relationship. As these deviations occur where the overpotential was highest, a slight surface potential change with bias is a possible explanation.

Moreover, we again have to emphasize the possible difference between bulk and surface defect chemistry. In accordance with the bulk-to-surface difference introduced above for electron holes and anodic current densities, we shifted the bulk Brouwer diagram by $160 \mathrm{meV}$ toward higher oxygen chemical potentials. Then we calculated the oxygen vacancy concentration of the more reduced surface for each 
experimental oxygen chemical potential, and the resulting plot is shown in Figure 9 (bottom). The current density vs oxygen vacancy concentration curves again show an approximate power law relation but with a higher exponent in the range of 2 . This dependence of the defect-related reaction order on the shift due to a more reduced surface shows that a final elucidation of the mechanism is problematic without a detailed knowledge of the surface defect concentrations. Still, to the best of our knowledge, the plot in Figure 9 gives the first semiquantitative relation between the oxygen reduction rate and the oxygen vacancy concentration determined for one and the same material. Thus far, similar plots (e.g., surface exchange coefficient vs vacancy concentration) were published only for different materials or doping levels. ${ }^{54,71}$

We may also consider the consistency of the main qualitative and semiquantitative conclusions drawn so far and thus can speculate about the reaction mechanism. First, it is consistent that all of the deduced reaction orders are comparatively high: for oxygen vacancies involved in oxygen reduction it is possibly two, for molecular oxygen in the gas phase it is one, and for electron holes during oxygen evolution it is very large; a value of more than six is found, which means that it is probably at least in the range of three to four or even larger. Finally, all reaction orders have to be in agreement with the thermodynamic mass action law, given by

$$
K=\frac{\left[\mathrm{O}_{\mathrm{O}}^{\mathrm{x}}\right]^{2}\left[\mathrm{Fe}_{\mathrm{Fe}}^{\bullet}\right]^{4}}{\left[\mathrm{~V}_{\mathrm{O}}^{\bullet \bullet}\right]^{2}\left[\mathrm{Fe}_{\mathrm{Fe}}^{\mathrm{x}}\right]^{4} p_{\mathrm{O}_{2}}}
$$

We can conclude that the measured reaction orders are indeed in acceptable agreement with this equation, which supports the consistency of our analysis. Please note: High reaction orders do not mean that many particles or defect species have to be involved in the rate-determining step. Rather, also species in fast preceding steps enter the rate equation. The reaction orders of gas (1) and oxygen vacancies (possibly 2) would be in accordance with incorporation of an adsorbed oxygen molecule into two neighboring vacancies as the ratelimiting step (probably accompanied by further reduction). However, only further studies may reveal the validity of this hypothesis.

Altogether, this example demonstrates that the analysis of measured $j\left(\eta, p_{\mathrm{O}_{2}}\right)$ data in terms of $j\left(\mu_{\mathrm{O}}, p_{\mathrm{O}_{2}}\right)$ allows important mechanistic conclusions. In our specific case of LSF electrodes, most effects can be explained by changes in either adsorbate or defect concentrations when varying overpotential and oxygen partial pressure. Accordingly, the measured nonlinearity of current density vs overpotential curves is largely the result of voltage-induced defect concentration changes. This is in strong contrast to a charge transfer-limited kinetics at aqueous/metal interfaces described by Butler-Volmer's equation. There electrostatic potential changes rather than concentration changes cause the nonlinearity of the often exponential current-voltage curve. Accordingly, analysis of solid-state electrochemical measurements cannot simply rely on established concepts from aqueous electrochemistry but has to implement novel analysis tools. The concept introduced in this paper may serve as the basis for future data analysis of similar experiments. It is applicable not only to other mixed conducting electrodes but also for investigating other electrochemical reactions such as water splitting or $\mathrm{CO}_{2}$ reduction.

\section{CONCLUSION}

A simple empirical analysis of $p_{\mathrm{O}_{2}}$ and overpotential-dependent oxygen exchange currents in terms of reaction orders may be highly misleading in mechanistic discussions. Current-overpotential curves of dense LSF thin films, for example, yield surprising results, such as an apparent reaction order of zero with respect to the oxygen partial pressure for oxygen reduction in high $p_{\mathrm{O}_{2}}$ or acceleration of oxygen evolution by increasing $p_{\mathrm{O}_{2}}$. For the analysis and mechanistic interpretation of such or similar experiments we propose a novel approach. In a first step, the oxygen chemical potential in the electrode is kept constant while analyzing the effect of the oxygen partial pressure on the oxygen evolution or incorporation current. A second step considers the dependence of these currents on the defect chemical state, defined by the oxygen chemical potential. The defect chemical state is varied by the overpotential at constant oxygen partial pressure. In this manner, the effects of the experimental parameters oxygen partial pressure and electrode overpotential can be deconvoluted, and the true dependencies of the oxygen reduction and evolution currents on the concentration of gas phase or adsorbate species and on the point defect concentrations can be obtained.

This way of analysis can become a powerful tool when aiming at a better mechanistic understanding of oxygen exchange reactions, as exemplified for LSF. For the oxygen evolution on LSF we found strong indication for a limitation by the electron hole concentration. Oxygen gas species or adsorbates had no effect at low $p_{\mathrm{O}_{2}}$ and even slowed the oxygen evolution reaction at higher oxygen pressures. For oxygen incorporation, a linear dependence of the oxygen reduction current on $p_{\mathrm{O}_{2}}$ via gas adsorbates was found for $p_{\mathrm{O}_{2}}$ up to 10 mbar. This indicates that a molecular oxygen species is involved in the rate-determining step. Additionally, a clear correlation between oxygen vacancy concentration and reaction rate could be deduced. Such a correlation was already hypothesized in the literature from measurement on different materials, but here experimental evidence is given for one and the same material. This strongly suggests oxygen vacancies as the rate-limiting defect species for oxygen reduction. Nonlinearities of the current voltage curves seem to be largely the result of voltage-induced changes in defect concentrations rather than due to electrostatic effects. To finally clarify the exact reaction mechanism on LSF a more detailed investigation of the defect chemistry of the perovskite surface is essential.

\section{ASSOCIATED CONTENT}

\section{S Supporting Information}

The Supporting Information is available free of charge on the ACS Publications website at DOI: 10.1021/acs.chemmater.8b00597.

Schematic of the 3 electrode sample, SEM cross section of an LSF film, impedance data and fit results, deduction of a rate equation (PDF)

(ZIP)

\section{AUTHOR INFORMATION}

\section{Corresponding Author}

*E-mail: alexander.e164.schmid@tuwien.ac.at.

ORCID

Alexander Schmid: 0000-0002-4457-4730 
Ghislain M. Rupp: 0000-0002-9241-3923

Notes

The authors declare no competing financial interest.

\section{ACKNOWLEDGMENTS}

The authors gratefully acknowledge funding by Austrian Science Fund (FWF) projects P4509-N16 and W1243-N16.

\section{REFERENCES}

(1) Ge, X. M.; Chan, S. H.; Liu, Q. L.; Sun, Q. Solid oxide fuel cell anode materials for direct hydrocarbon utilization. Adv. Energy Mater. 2012, 2, 1156-1181.

(2) Jun, A.; Kim, J.; Shin, J.; Kim, G. Perovskite as a Cathode Material: A Review of its Role in Solid-Oxide Fuel Cell Technology. ChemElectroChem 2016, 3, 511-530.

(3) Laguna-Bercero, M. A. Recent advances in high temperature electrolysis using solid oxide fuel cells: A review. J. Power Sources 2012, 203, 4-16.

(4) Mahato, N.; Banerjee, A.; Gupta, A.; Omar, S.; Balani, K. Progress in material selection for solid oxide fuel cell technology: A review. Prog. Mater. Sci. 2015, 72, 141-337.

(5) Rahman, I. Z.; Raza, M. A.; Rahman, M. A. Perovskite Based Anode Materials for Solid Oxide Fuel Cell Application: A Review. Adv. Mater. Res. 2012, 445, 497-502.

(6) Sun, C.; Hui, R.; Roller, J. Cathode materials for solid oxide fuel cells: A review. J. Solid State Electrochem. 2010, 14, 1125-1144.

(7) Sun, C.; Stimming, U. Recent anode advances in solid oxide fuel cells. J. Power Sources 2007, 171, 247-260.

(8) Timurkutluk, B.; Timurkutluk, C.; Mat, M. D.; Kaplan, Y. A review on cell/stack designs for high performance solid oxide fuel cells. Renewable Sustainable Energy Rev. 2016, 56, 1101-1121.

(9) Xia, C.; Liu, M. Novel cathodes for low-temperature solid oxide fuel cells. Adv. Mater. 2002, 14, 521-523.

(10) Ralph, J. M.; Rossignol, C.; Kumar, R. Cathode Materials for Reduced-Temperature SOFCs. J. Electrochem. Soc. 2003, 150, A1518A1522.

(11) De Souza, R. Oxygen transport in $\mathrm{La}_{1-\mathrm{x}} \mathrm{Sr}_{\mathrm{x}} \mathrm{Mn}_{1-\mathrm{y}} \mathrm{Co}_{\mathrm{y}} \mathrm{O}_{3 \pm \delta}$ perovskites Part I. Oxygen tracer diffusion. Solid State Ionics 1998, 106, 175-187.

(12) Chen, X. J.; Khor, K. A.; Chan, S. H. Electrochemical behavior of $\mathrm{La}(\mathrm{Sr}) \mathrm{MnO}_{3}$ electrode under cathodic and anodic polarization. Solid State Ionics 2004, 167, 379-387.

(13) Fleig, J.; Kim, H. R.; Jamnik, J.; Maier, J. Oxygen reduction kinetics of Lanthanum Manganite (LSM) model cathodes: Partial pressure dependence and rate-limiting steps. Fuel Cells 2008, 8, 330337.

(14) Mastrikov, Y. A.; Merkle, R.; Heifets, E.; Kotomin, E. A.; Maier, J. Pathways for oxygen incorporation in mixed conducting perovskites: A DFT-based Mechanistic analysis for $(\mathrm{La}, \mathrm{Sr}) \mathrm{MnO}_{3-\delta}$. J. Phys. Chem. C 2010, 114, 3017-3027.

(15) Steele, B. Properties of $\mathrm{La}_{0.6} \mathrm{Sr}_{0.4} \mathrm{Co}_{0.2} \mathrm{Fe}_{0.8} \mathrm{O}_{3-\delta}$ (LSCF) double layer cathodes on gadolinium-doped cerium oxide (CGO) electrolytes II. Role of oxygen exchange and diffusion. Solid State Ionics 1998, 106, 255-261.

(16) Bahteeva, J.; Leonidov, I.; Patrakeev, M.; Mitberg, E.; Kozhevnikov, V.; Poeppelmeier, K. High-temperature ion transport in $\mathrm{La}_{1-\mathrm{x}} \mathrm{Sr}_{\mathrm{x}} \mathrm{FeO}_{3-\delta}$. J. Solid State Electrochem. 2004, 8, 578-584.

(17) Baumann, F. S.; Fleig, J.; Cristiani, G.; Stuhlhofer, B.; Habermeier, H.-U.; Maier, J. Quantitative Comparison of Mixed Conducting SOFC Cathode Materials by Means of Thin Film Model Electrodes. J. Electrochem. Soc. 2007, 154, B931-B941.

(18) Baumann, F. S.; Maier, J.; Fleig, J. The polarization resistance of mixed conducting SOFC cathodes: A comparative study using thin film model electrodes. Solid State Ionics 2008, 179, 1198-1204.

(19) Baumann, F. S.; Fleig, J.; Konuma, M.; Starke, U.; Habermeier, H.-U.; Maier, J. Strong Performance Improvement of $\mathrm{La}_{0.6} \mathrm{Sr}_{0.4} \mathrm{Co}_{0.8} \mathrm{Fe}_{0.2} \mathrm{O}_{3-\delta}$ SOFC Cathodes by Electrochemical Activation. J. Electrochem. Soc. 2005, 152, A2074-A2079.
(20) Baumann, F. S.; Fleig, J.; Habermeier, H. U.; Maier, J. Impedance spectroscopic study on well-defined $(\mathrm{La}, \mathrm{Sr})(\mathrm{Co}, \mathrm{Fe}) \mathrm{O}_{3-\delta}$ model electrodes. Solid State Ionics 2006, 177, 1071-1081.

(21) Bongio, E. V.; Black, H.; Raszewski, F. C.; Edwards, D.; Mcconville, C. J.; Amarakoon, V. R. W. Microstructural and HighTemperature Electrical Characterization of $\mathrm{La}_{1-\mathrm{x}} \mathrm{Sr}_{\mathrm{x}} \mathrm{FeO}_{3-\delta}$. Fuel Cells 2005, 14, 193-198.

(22) Bucher, E.; Sitte, W. Defect chemical modeling of (La, Sr)(Co, $\mathrm{Fe}) \mathrm{O}_{3-\delta}$. J. Electroceram. 2004, 13, 779-784.

(23) Kawada, T.; Suzuki, J.; Sase, M.; Kaimai, A.; Yashiro, K.; Nigara, Y.; Mizusaki, J.; Kawamura, K.; Yugami, H. Determination of Oxygen Vacancy Concentration in a Thin Film of $\mathrm{La}_{0.6} \mathrm{Sr}_{0.4} \mathrm{CoO}_{3-\delta}$ by an Electrochemical Method. J. Electrochem. Soc. 2002, 149, E252-E259.

(24) Kim, M. C.; Park, S.; Haneda, H.; Tanaka, J.; Shirasaki, S. High temperature electrical conductivity of $\mathrm{La}_{1-\mathrm{x}} \mathrm{Sr}_{\mathrm{x}} \mathrm{FeO}_{3-\delta}(x>0.5)$. Solid State Ionics 1990, 40-41, 239-243.

(25) Kogler, S.; Nenning, A.; Rupp, G. M.; Opitz, A. K.; Fleig, J. Comparison of Electrochemical Properties of $\mathrm{La}_{06} \mathrm{Sr}_{04} \mathrm{FeO}_{3-\delta}$ Thin Film Electrodes: Oxidizing vs. Reducing Conditions. J. Electrochem. Soc. 2015, 162, F317-F326.

(26) Kubicek, M.; Huber, T. M.; Welzl, A.; Penn, A.; Rupp, G. M.; Bernardi, J.; Stöger-Pollach, M.; Hutter, H.; Fleig, J. Electrochemical properties of $\mathrm{La}_{0.6} \mathrm{Sr}_{0.4} \mathrm{FeO}_{3-\delta}$ thin films investigated by complementary impedance spectroscopy and isotope exchange depth profiling. Solid State Ionics 2014, 256, 38-44.

(27) Mirzababaei, J.; Chuang, S. $\mathrm{La}_{0.6} \mathrm{Sr}_{0.4} \mathrm{Co}_{0.2} \mathrm{Fe}_{0.8} \mathrm{O}_{3-\delta}$ Perovskite: A Stable Anode Catalyst for Direct Methane Solid Oxide Fuel Cells. Catalysts 2014, 4, 146-161.

(28) Kuhn, M.; Hashimoto, S.; Sato, K.; Yashiro, K.; Mizusaki, J. Oxygen nonstoichiometry, thermo-chemical stability and lattice expansion of $\mathrm{La}_{0.6} \mathrm{Sr}_{0.4} \mathrm{FeO}_{3-\delta}$. Solid State Ionics 2011, 195, 7-15.

(29) Mizusaki, J.; Sasamoto, T.; Cannon, W. R.; Bowen, H. K. Electronic Conductivity, Seebeck Coefficient, and Defect Structure of $\mathrm{La}_{1-\mathrm{x}} \mathrm{Sr}_{\mathrm{x}} \mathrm{FeO}_{3-\delta}(\mathrm{x}=0.1,0.25)$. J. Am. Ceram. Soc. 1983, 66, 247-252.

(30) Nenning, A.; Opitz, A. K.; Rameshan, C.; Rameshan, R.; Blume, R.; Hävecker, M.; Knop-Gericke, A.; Rupprechter, G.; Klötzer, B.; Fleig, J. Ambient pressure XPS study of mixed conducting perovskitetype SOFC cathode and anode materials under well-defined electrochemical polarization. J. Phys. Chem. C 2016, 120, 1461-1471.

(31) Opitz, A. K.; Nenning, A.; Rameshan, C.; Rameshan, R.; Blume, R.; Hävecker, M.; Knop-Gericke, A.; Rupprechter, G.; Fleig, J.; Klötzer, B. Enhancing electrochemical water-splitting kinetics by polarizationdriven formation of near-surface iron(0): An in situ XPS study on perovskite-type electrodes. Angew. Chem., Int. Ed. 2015, 54, 26282632.

(32) Patrakeev, M. V.; Leonidov, I. A.; Kozhevnikov, V. L.; Poeppelmeier, K. R. p-type electron transport in $\mathrm{La}_{1-x} \mathrm{Sr}_{\mathrm{x}} \mathrm{FeO}_{3-\delta}$ at high temperatures. J. Solid State Chem. 2005, 178, 921-927.

(33) Rupp, G. M.; Téllez, H.; Druce, J.; Limbeck, A.; Ishihara, T.; Kilner, J.; Fleig, J. Surface chemistry of $\mathrm{La}_{0.6} \mathrm{Sr}_{0.4} \mathrm{CoO}_{3-\delta}$ thin films and its impact on the oxygen surface exchange resistance. J. Mater. Chem. A 2015, 3, 22759-22769.

(34) Rupp, G. M.; Schmid, A.; Nenning, A.; Fleig, J. The Superior Properties of $\mathrm{La}_{0.6} \mathrm{Ba}_{0.4} \mathrm{CoO}_{3-\delta}$ Thin Film Electrodes for Oxygen Exchange in Comparison to $\mathrm{La}_{0.6} \mathrm{Sr}_{0.4} \mathrm{CoO}_{3-\delta}$. J. Electrochem. Soc. 2016, 163, F564-F573.

(35) Sase, M.; Suzuki, J.; Yashiro, K.; Otake, T.; Kaimai, A.; Kawada, T.; Mizusaki, J.; Yugami, H. Electrode reaction and microstructure of $\mathrm{La}_{0.6} \mathrm{Sr}_{0.4} \mathrm{CoO}_{3-\delta}$ thin films. Solid State Ionics 2006, 177, 1961-1964.

(36) ten Elshof, J. E. Oxygen Exchange and Diffusion Coefficients of Strontium-Doped Lanthanum Ferrites by Electrical Conductivity Relaxation. J. Electrochem. Soc. 1997, 144, 1060-1067.

(37) Tsvetkov, N.; Lu, Q.; Sun, L.; Crumlin, E. J.; Yildiz, B. Improved chemical and electrochemical stability of perovskite oxides with less reducible cations at the surface. Nat. Mater. 2016, 15, 1010-1016.

(38) Wang, H.; Yakal-Kremski, K. J.; Yeh, T.; Rupp, G. M.; Limbeck, A.; Fleig, U.; Barnett, S. A. Mechanisms of Performance Degradation of $(\mathrm{La}, \mathrm{Sr})(\mathrm{Co}, \mathrm{Fe}) \mathrm{O}_{3-\delta}$ Solid Oxide Fuel Cell Cathodes. J. Electrochem. Soc. 2016, 163, F581-F585. 
(39) Yoo, J.; Verma, A.; Wang, S.; Jacobson, A. J. Oxygen Transport Kinetics in $\mathrm{SrFeO}_{3}, \mathrm{La}_{0.5} \mathrm{Sr}_{0.5} \mathrm{FeO}_{3-\delta}$, and $\mathrm{La}_{0.2} \mathrm{Sr}_{0.8} \mathrm{Cr}_{0.8} \mathrm{Fe}_{0.2} \mathrm{O}_{3-\delta}$ Measured by Electrical Conductivity Relaxation. J. Electrochem. Soc. 2005, 152, A497-A505.

(40) Yan, A.; Cheng, M.; Dong, Y.; Yang, W.; Maragou, V.; Song, S.; Tsiakaras, P. Investigation of a $\mathrm{Ba}_{0.5} \mathrm{Sr}_{0.5} \mathrm{Co}_{0.8} \mathrm{Fe}_{0.2} \mathrm{O}_{3-\delta}$ based cathode IT-SOFC I. The effect of $\mathrm{CO}_{2}$ on the cell performance. Appl. Catal., B 2006, 66, 64-71.

(41) Vente, J. F.; McIntosh, S.; Haije, W. G.; Bouwmeester, H. J. M. Properties and performance of $\mathrm{Ba}_{\mathrm{x}} \mathrm{Sr}_{1-\mathrm{x}} \mathrm{Co}_{0.8} \mathrm{Fe}_{0.2} \mathrm{O}_{3-\delta}$ materials for oxygen transport membranes. J. Solid State Electrochem. 2006, 10, $581-588$.

(42) Gangopadhayay, S.; Inerbaev, T.; Masunov, A. E.; Altilio, D.; Orlovskaya, N. Structural characterization combined with the first principles simulations of barium/strontium cobaltite/ferrite as promising material for solid oxide fuel cells cathodes and hightemperature oxygen permeation membranes. ACS Appl. Mater. Interfaces 2009, 1, 1512-1519.

(43) Lee, S.; Lim, Y.; Lee, E. A.; Hwang, H. J.; Moon, J. W. $\mathrm{Ba}_{0.5} \mathrm{Sr}_{0.5} \mathrm{Co}_{0.8} \mathrm{Fe}_{0.2} \mathrm{O}_{3-\delta}$ (BSCF) and $\mathrm{La}_{0.6} \mathrm{Ba}_{0.4 \mathrm{C}} \mathrm{O}_{0.2} \mathrm{Fe}_{0.8} \mathrm{O}_{3-\delta}$ (LBCF) cathodes prepared by combined citrate-EDTA method for IT-SOFCs. J. Power Sources 2006, 157, 848-854.

(44) Niedrig, C.; Taufall, S.; Burriel, M.; Menesklou, W.; Wagner, S. F.; Baumann, S.; Ivers-Tiffee, E. Thermal stability of the cubic phase in $\mathrm{Ba}_{0.5} \mathrm{Sr}_{0.5} \mathrm{Co}_{0.8} \mathrm{Fe}_{0.2} \mathrm{O}_{3-\delta}$ (BSCF)1. Solid State Ionics 2011, 197, 25-31.

(45) Baumann, F. S.; Fleig, J.; Habermeier, H. U.; Maier, J. $\mathrm{Ba}_{0.5} \mathrm{Sr}_{0.5} \mathrm{Co}_{0.8} \mathrm{Fe}_{0.2} \mathrm{O}_{3-\delta}$ thin film microelectrodes investigated by impedance spectroscopy. Solid State Ionics 2006, 177, 3187-3191.

(46) Adler, S. Mechanism and kinetics of oxygen reduction on porous $\mathrm{La}_{1-\mathrm{x}} \mathrm{Sr}_{\mathrm{x}} \mathrm{CoO}_{3-\delta}$ electrodes. Solid State Ionics 1998, 111, 125134.

(47) Adler, S. B.; Chen, X. Y.; Wilson, J. R. Mechanisms and rate laws for oxygen exchange on mixed-conducting oxide surfaces. J. Catal. 2007, 245, 91-109.

(48) Guan, Z.; Chen, D.; Chueh, W. C. Analyzing the dependence of oxygen incorporation current density on overpotential and oxygen partial pressure in mixed conducting oxide electrodes. Phys. Chem. Chem. Phys. 2017, 19, 23414-23424.

(49) Fleig, J. On the current-voltage characteristics of charge transfer reactions at mixed conducting electrodes on solid electrolytes. Phys. Chem. Chem. Phys. 2005, 7, 2027-2037.

(50) Merkle, R.; Maier, J. Oxygen incorporation into Fe-doped

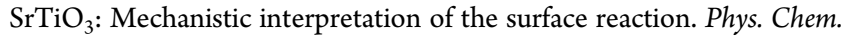
Chem. Phys. 2002, 4, 4140-4148.

(51) Miyoshi, S.; Takeshita, A.; Okada, S.; Yamaguchi, S. Ratedetermining elementary step of oxygen reduction reaction at $(\mathrm{La}, \mathrm{Sr}) \mathrm{CoO}_{3}$-based cathode surface. Solid State Ionics 2016, 285, 202-208.

(52) Mosleh, M.; Søgaard, M.; Hendriksen, P. V. Kinetics and Mechanisms of Oxygen Surface Exchange on $\mathrm{La}_{0.6} \mathrm{Sr}_{0.4} \mathrm{FeO}_{3-\delta}$ Thin Films. J. Electrochem. Soc. 2009, 156, B441.

(53) Wang, L.; Merkle, R.; Mastrikov, Y. A.; Kotomin, E. A.; Maier, J. Oxygen exchange kinetics on solid oxide fuel cell cathode materialsgeneral trends and their mechanistic interpretation. J. Mater. Res. 2012, 27, 2000-2008.

(54) Wang, L.; Merkle, R.; Maier, J. Surface Kinetics and Mechanism of Oxygen Incorporation Into $\mathrm{La}_{1-x} \mathrm{Sr}_{\mathrm{x}} \mathrm{Co}_{\mathrm{y}} \mathrm{Fe}_{1-\mathrm{y}} \mathrm{O}_{3-\delta} \mathrm{SOFC}$ Microelectrodes. J. Electrochem. Soc. 2010, 157, B1802-B1808.

(55) Fleig, J.; Merkle, R.; Maier, J. The $\mathrm{p}\left(\mathrm{O}_{2}\right)$ dependence of oxygen surface coverage and exchange current density of mixed conducting oxide electrodes: model considerations. Phys. Chem. Chem. Phys. 2007, 9, 2713.

(56) Kawada, T.; Masuda, K.; Suzuki, J. Oxygen isotope exchange with a dense $\mathrm{La}_{0.6} \mathrm{Sr}_{0.4} \mathrm{CoO}_{3-\delta}$ electrode on a $\mathrm{Ce}_{0.9} \mathrm{Gd}_{0.1} \mathrm{O}_{1.9}$ electrolyte. Solid State Ionics 1999, 121, 271-279.

(57) Tu, H.; Takeda, Y.; Imanishi, N.; Yamamoto, O. $\mathrm{Ln}_{0.6} \mathrm{Sr}_{0.4} \mathrm{Co}_{0.8} \mathrm{Fe}_{0.2} \mathrm{O}_{3-\delta}$ ( $\left.\mathrm{Ln}=\mathrm{La}, \mathrm{Pr}, \mathrm{Nd}, \mathrm{Sm}, \mathrm{Gd}\right)$ for the electrode in solid oxide fuel cells. Solid State Ionics 1999, 117, 277-281.
(58) Winkler, J.; Hendriksen, P.; Bonanos, N.; Mogensen, M. Geometric Requirements of Solid Electrolyte Cells with a Reference Electrode. J. Electrochem. Soc. 1998, 145, 1184-1192.

(59) Fletcher, S. The two-terminal equivalent network of a threeterminal electrochemical cell. Electrochem. Commun. 2001, 3, 692-696.

(60) Fafilek, F.; Breiter, M. W. Instrumentation for ac four-probe measurements of large impedances. J. Electroanal. Chem. 1997, 430, 269-278.

(61) Fafilek, G. The use of voltage probes in impedance spectroscopy. Solid State Ionics 2005, 176, 2023-2029.

(62) Hsieh, G.; Mason, T.; Pederson, L. Experimental limitations in impedance spectroscopy: Part II. Electrode artifacts three poit measurements on Pt/YSZ. Solid State Ionics 1996, 91, 203-212.

(63) Hsieh, G.; Ford, S. J.; Mason, T. O.; Pederson, L. R. Experimental limitations in impedance spectroscopy: Part I Simulation of reference electrode artifacts in three-point measurements. Solid State Ionics 1996, 91, 191-201.

(64) Chueh, W. C.; Haile, S. M. Electrochemical studies of capacitance in cerium oxide thin films and its relationship to anionic and electronic defect densities. Phys. Chem. Chem. Phys. 2009, 11, 8144-8148.

(65) Fleig, J.; Rupp, G. M.; Nenning, A.; Schmid, A. Towards an Improved Understanding of Electrochemical Oxygen Exchange Reactions on Mixed Conducting Oxides. ECS Trans. 2017, 77, 93108.

(66) Brug, G. J.; van den Eeden, A. L.; Sluyters-Rehbach, M.; Sluyters, J. H. The analysis of electrode impedances complicated by the presence of a constant phase element. J. Electroanal. Chem. Interfacial Electrochem. 1984, 176, 275-295.

(67) Schmid, A.; Rupp, G. M.; Fleig, J. Voltage and partial pressure dependent defect chemistry in $(\mathrm{La}, \mathrm{Sr}) \mathrm{FeO}_{3-\delta}$ thin films investigated by chemical capacitance measurements. Phys. Chem. Chem. Phys. 2018, 20, 12016-12026.

(68) Mizusaki, J.; Yoshihiro, M.; Yamauchi, S.; Fueki, K. Nonstoichiometry and defect structure of the perovskite-type oxides $\mathrm{La}_{1-\mathrm{x}} \mathrm{Sr}_{\mathrm{x}} \mathrm{FeO}_{3-\delta}$. J. Solid State Chem. 1985, 58, 257-266.

(69) Mizusaki, J.; Yoshihiro, M.; Yamauchi, S.; Fueki, K. Thermodynamic quantities and defect equilibrium in the perovskitetype oxide solid solution $\mathrm{La}_{1-\mathrm{x}} \mathrm{Sr}_{\mathrm{x}} \mathrm{FeO}_{3-\delta}$. J. Solid State Chem. 1987, 67, $1-8$.

(70) Read, M. S. D.; Saiful Islam, M.; Watson, G. W.; King, F.; Hancock, F. E. Defect chemistry and surface properties of $\mathrm{LaCoO}_{3}$.J. Mater. Chem. 2000, 10, 2298-2305.

(71) Kuklja, M. M.; Kotomin, E. a.; Merkle, R.; Mastrikov, Y. a.; Maier, J. Combined theoretical and experimental analysis of processes determining cathode performance in solid oxide fuel cells. Phys. Chem. Chem. Phys. 2013, 15, 5443-5471. 